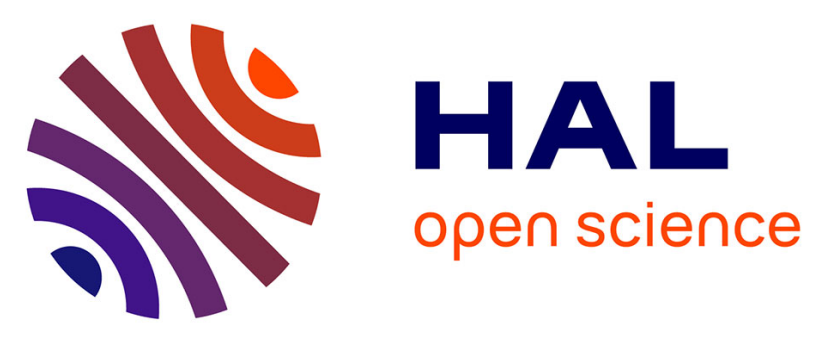

\title{
Strong Dependence of the Linewidth Enhancement Factor onto an externally injected optical signal for locked Fabry-Perot Laser Diodes
}

\author{
Quoc Thai Nguyen, Pascal Besnard, Olivier Vaudel, Alexandre Shen, \\ Guang-Hua Duan
}

\section{To cite this version:}

Quoc Thai Nguyen, Pascal Besnard, Olivier Vaudel, Alexandre Shen, Guang-Hua Duan. Strong Dependence of the Linewidth Enhancement Factor onto an externally injected optical signal for locked Fabry-Perot Laser Diodes. Conference on Lasers and Electro Optics / European Quantum Electronics Conference 2009 (CLEO Europe/EQEC 2009), Jun 2009, Munich, Germany. pp.CB9.3, 10.1109/CLEOE-EQEC.2009.5191594 . hal-00497259

\section{HAL Id: hal-00497259 \\ https://hal.science/hal-00497259}

Submitted on 2 Jul 2010

HAL is a multi-disciplinary open access archive for the deposit and dissemination of scientific research documents, whether they are published or not. The documents may come from teaching and research institutions in France or abroad, or from public or private research centers.
L'archive ouverte pluridisciplinaire HAL, est destinée au dépôt et à la diffusion de documents scientifiques de niveau recherche, publiés ou non, émanant des établissements d'enseignement et de recherche français ou étrangers, des laboratoires publics ou privés. 


\title{
Strong Dependence of the Linewidth Enhancement Factor onto an externally injected optical signal for locked Fabry-Perot Laser Diodes
}

\author{
Quoc-Thai Nguyen ${ }^{1}$, Pascal Besnard ${ }^{1}$, Olivier Vaudel ${ }^{1}$, Alexandre Shen ${ }^{2}$, Guang-Hua Duan ${ }^{2}$ \\ 1. FOTON - ENSSAT, CNRS UMR 6082, 6 rue de Kerampont, BP 80518, 22305 Lannion Cedex, France \\ 2. Alcatel Thales III-V Lab, Route Départementale 128, Avenue de la Vauve, 91767 Palaiseau Cedex, France
}

Injection-locking is based on the fact that the laser can be locked onto the frequency and the phase of an external injected optical signal. When a Fabry-Perot laser diode (FP LD) is locked onto a single-mode signal, its operation becomes single-mode. The injection-locked FP LD (IL-FP LD) has been proposed as a standard component for optical access network [1]. In this paper, we propose to study the Linewidth Enhancement Factor (LEF) of IL-FP LD and its dependence onto the injection parameters.

The experimental setup of IL-FP LD is represented in fig. 1. A tunable laser delivers a CW signal, which is injected into the FP LD through an optical circulator. A variable attenuator is used to adjust the injected optical power. Fig. 2a represents the optical spectra of the free-running FP LD biased at $80 \mathrm{~mA}$ (2 Ith) and of the IL-FP LD. The external signal is operating at $1550.1 \mathrm{~nm}$ wavelength and with an optical power of $0 \mathrm{dBm}$ inside the laser cavity. An extinction ratio higher than $20 \mathrm{~dB}$ is achieved between the side modes in the locking regime. The normalized electro-optical responses of free-running FP LD and of IL-FP LD at $1550.2 \mathrm{~nm}$ are shown in fig. $2 b$ for different injected powers. One can note the usual enhancement of the resonance frequency along with injected power. However, the laser bandwidth is limited even in the case of injection locking because of low frequency roll-off pole [2]. Increasing the bias current of IL-FP LD could theoretically improve the roll-off, but at the expense of the locking bandwidth, which is not desirable.

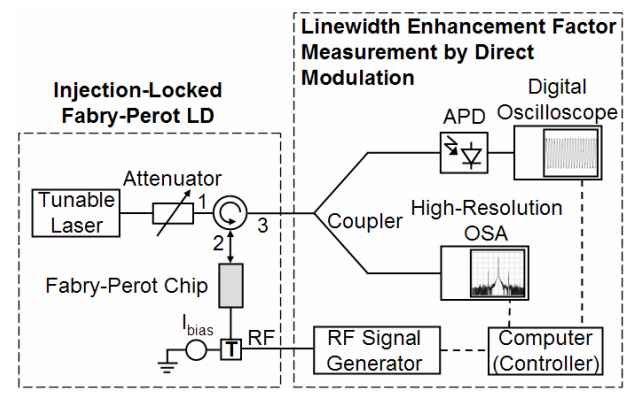

Fig. 1 Sketch of the experimental setup

The LEF is measured using a direct modulation technique as shown in the right part of figure 1. The LEF is obtained as the ratio of frequency modulation (FM) over amplitude modulation (AM) [3]. The AM index is measured with a digital oscilloscope. The FM index is obtained thanks to a highresolution optical spectrum analyzer (1 $\mathrm{MHz}$ ), by measuring the ratio between first order sidebands and optical carrier.
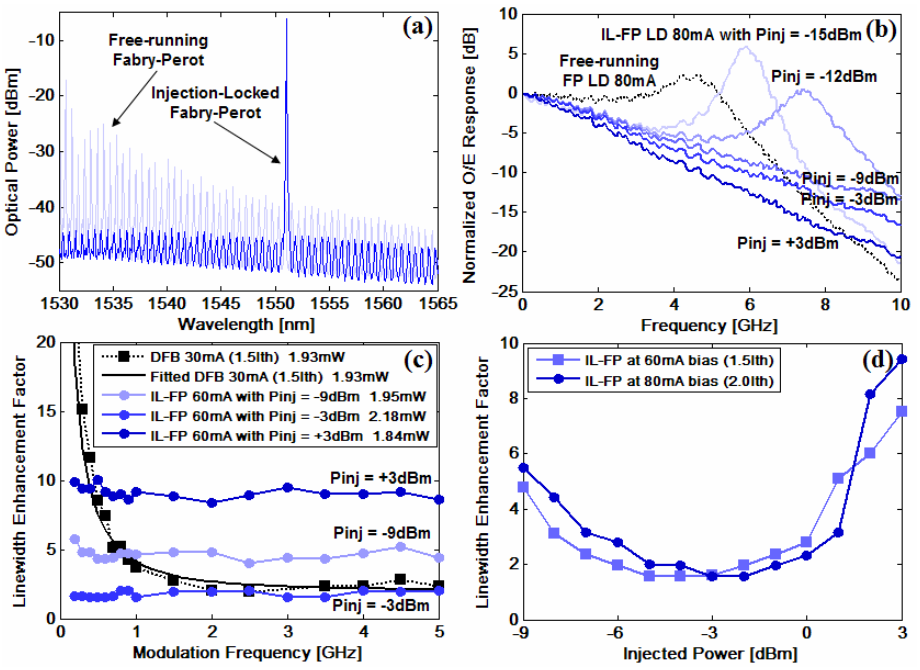

Fig. 2 (a) The optical spectra of the FP LD and of the IL-FP LD (b) The electrooptical responses of the FP LD and of the IL-FP LD at different injected powers (c) The LEF vs. modulation frequency of the IL-FP LD at different injected powers compared to one of a MQW DFB (d) The LEF of the IL-FP LD vs. injected power

Fig. 2c represents the LEF as a function of the modulation frequency applied to the IL-FP LD for different injected powers at $1550.1 \mathrm{~nm}$ and its comparison with a directly modulated SLMQW DFB laser. The AM index is always fixed at 5\%. A transient chirp of 1.98 and an adiabatic chirp of $26.7 \mathrm{GHz} / \mathrm{mW}$ are inferred from the theoretically fitted curve for SLMQW DFB laser [4]. The LEF of IL-FP LD is relatively constant along with modulation frequency, which means that the IL-FP LD presents a low adiabatic chirp and a transient chirp approximated to the LEF value. The variation of LEF (thus of transient chirp) as a function of injected power is shown in fig. 2d. Increasing the injected power tends to decrease the LEF. It can be understood as the decrease of the carrier density and thus of the index variation when the injected power is increased [5]. However, for higher injected power, the LEF tends to increase, which is probably caused by the nonlinear gain due to saturation at high injected power [6].

\section{References}

[1] Xu, Z.; Wen, Y. J.; Chae, C.; Wang, Y.; Lu, C., Opt. Fiber Comm. Conf., OFC 2006, OSA, pp.1-3, 5-10 March 2006, JThB72

[2] Lau, E.K.; Xiaoxue Zhao; Chang-Hasnain, C.; Wu, M.C., 21 It Int. Semi. Laser Conf., ISLC 2008, IEEE, pp.171-172, 14-18 Sept. 2008

[3] C.Harder, K.Vahala, A.Yariv, Appl. Phys. Lett., 42, pp. 328- 330, 1983

[4] Bjerkan, L.; Royset, A.; Hafskjaer, L.; Myhre, D., Journal of Lightwave Technol., vol.14, no.5, pp.839-850, May 1996

[5] Bo Zhang et al., Opt. Fiber Comm. Conf., OFC 2008, OSA, pp.1-3, 24-28 Feb. 2008, OWT7

[6] Agrawal, G.P., Photon. Technol. Lett., IEEE, vol.1, no.8, pp.212-214, Aug 1989 